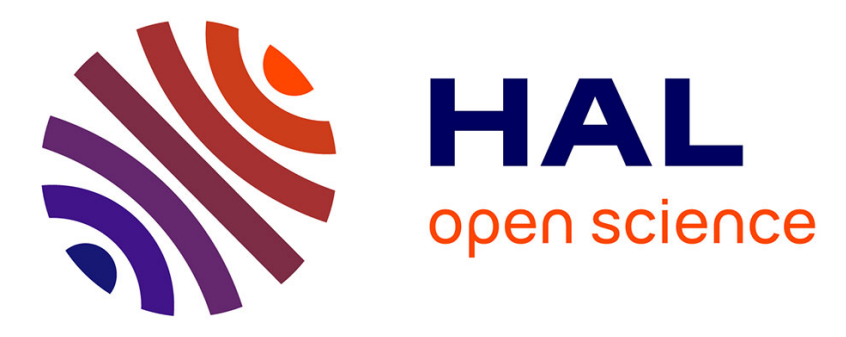

\title{
Experimental Magnetic Field Mapping of a Polycrystalline Superconducting YBCO Disc for an Axial Flux Motor
}

David Inácio, João Murta Pina, José Maria Ceballos, Mário Ventim Neves, Alfredo Álvarez

\section{To cite this version:}

David Inácio, João Murta Pina, José Maria Ceballos, Mário Ventim Neves, Alfredo Álvarez. Experimental Magnetic Field Mapping of a Polycrystalline Superconducting YBCO Disc for an Axial Flux Motor. 6th Doctoral Conference on Computing, Electrical and Industrial Systems (DoCEIS), Apr 2015, Costa de Caparica, Portugal. pp.467-474, 10.1007/978-3-319-16766-4_50 . hal-01343520

\section{HAL Id: hal-01343520 \\ https://inria.hal.science/hal-01343520}

Submitted on 8 Jul 2016

HAL is a multi-disciplinary open access archive for the deposit and dissemination of scientific research documents, whether they are published or not. The documents may come from teaching and research institutions in France or abroad, or from public or private research centers.
L'archive ouverte pluridisciplinaire HAL, est destinée au dépôt et à la diffusion de documents scientifiques de niveau recherche, publiés ou non, émanant des établissements d'enseignement et de recherche français ou étrangers, des laboratoires publics ou privés.

\section{(c)(1)}

Distributed under a Creative Commons Attribution| 4.0 International License 


\title{
Experimental Magnetic Field Mapping of a Polycrystalline Superconducting YBCO Disc for an Axial Flux Motor
}

\author{
David Inácio $^{1}$, João Murta Pina ${ }^{1}$, José M. Ceballos ${ }^{2}$, Mário Ventim Neves ${ }^{1}$, Alfredo \\ Álvarez ${ }^{2}$ \\ ${ }^{1}$ CTS, Uninova, Departamento de Engenharia Electrotécnica, Faculdade de Ciências e \\ Tecnologia, FCT, Universidade Nova de Lisboa, 2829-516 Caparica, Portugal \\ ${ }^{2}$ Departament of Electrical Engineering, Escuela de Ingenierias Industriales, Universidad de \\ Extremadura, E-06006 Badajoz, Spain
}

\begin{abstract}
The method of creating large and complex-shaped melt-textured YBCO bulks based in artificial welding seeds opens the door to the study of applications with polycrystalline superconductor samples. In order to evaluate the superconducting quality of the bulks, Hall probe mapping can be applied in order to measure trapped flux field profiles after magnetisation. This paper describes the magnetic field mapping of an axial flux motor with a polycrystalline high temperature superconductor (YBCO) disc rotor at liquid nitrogen temperature $(77 \mathrm{~K})$. An axial flux hall probe is used and magnetic field profiles have been obtained for different polar configurations of a three-phase stator winding which will be operated at $50 \mathrm{~Hz}$. After the magnetization of the HTS disc trapped flux is measured, and its magnitude depends on the polar configuration and magnitude of the applied field.
\end{abstract}

Keywords: High temperature superconducting motor, polycrystalline YBCO, axial flux disc motor, magnetic field mapping.

\section{Introduction}

The application of melt-textured YBCO in power applications (motors, transformers, current limiters, etc.) requires manufacturing complex-shaped pieces, some with large sizes. Such large bulks are usually build using artificial welding of separate monograins from it, grown by the Top-Seeding technique. Different joining techniques have been proposed, based on the use of low-melting point welding agents like oxides [1] or $\mathrm{YBCO} / \mathrm{Ag}$ composites [2]. Recently, new methodologies based on surface melting have been developed, leading to high quality welds [3]. The need to evaluate the quality of the superconducting joins has stimulated the development of different experimental characterization methods, as Hall probe mapping magnetometry [4].

The operation of the HTS disc motor is based in the vortex's dynamics within the HTS material due to the magnetic field variations imposed by the three-phase supply. The field in the HTS material depends on its magnetic history, exhibiting several 
magnetic excursion that defines the operation regimes of the motor: in the synchronous regime, the rotor is synchronous with the stator rotating magnetic field due to trapped flux; however, in the asynchronous regime the rotor's magnetic field slides over it and flux flow is present, leading to losses and, consequently, torque. For the asynchronous regime, the torque is given by (1) [5], and is maximum when the rotor is all magnetized.

$$
T=\frac{p^{2}}{2 \pi} P_{H / c i c l e}
$$

Since torque proportional to the losses in the HTS material, it is useful that as much HTS material as possible gets penetrated by flux in order to take advantage of the disc size. For that reason, a research question is defined, namely "Is it possible to magnetise all the HTS material?".

\section{Relationship to Cloud-based Solutions}

Mapping of trapped flux in an HTS disc material is showed in this paper. In order to observe if all the material is magnetized, several mappings were obtained for different poles configurations. All the obtained results could be shared in a cloud-based system allowing other researchers to perform analysis, and providing data backup an on-time data monitoring.

\section{Hall Measurement System}

In order to observe the magnetization of the rotor, a Hall probe magnetic mapping system was developed allowing obtaining field profile in a matrix of points. It consists in a three-dimensional computer-controlled positioner connected to an axial flux hall probe attached to a mechanical arm which, after the rotor's magnetization, collects the magnetic field data. The system is showed in Fig. 1.

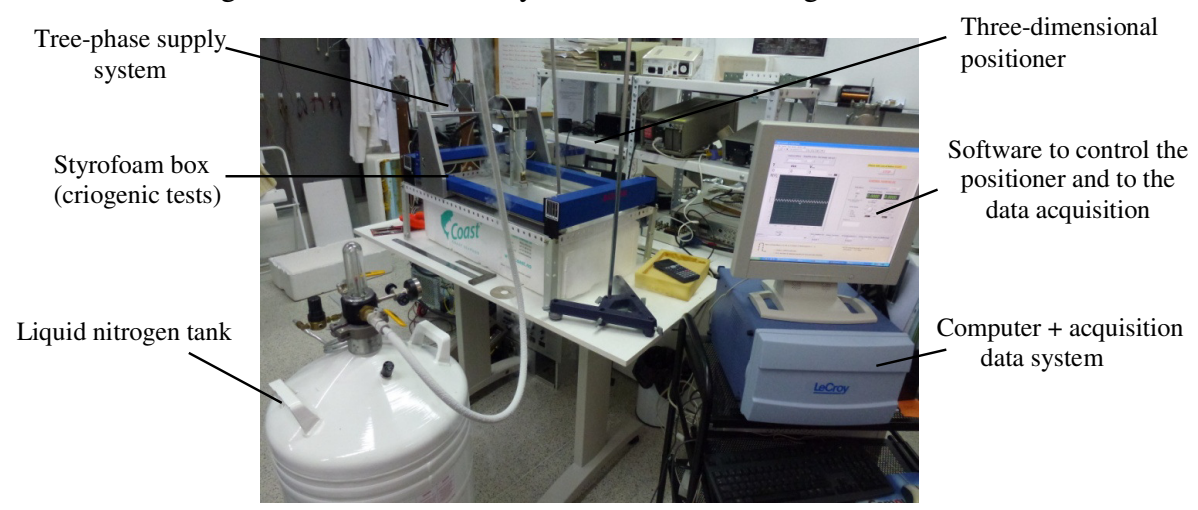

Fig. 1. Experimental apparatus for the static test of the HTS rotor. 


\section{Topology of the Motor}

The built disc motor is composed by two $20 \mathrm{~cm}$ diameter semi-stators with 24 slots and 24 conventional cooper windings each one, a steel shaft, a rotor consisting of a 20 $\mathrm{cm}$ diameter YBCO disc, two support bearings and fixing screws. Fig. 2 shows the device.

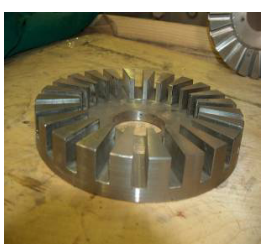

a)

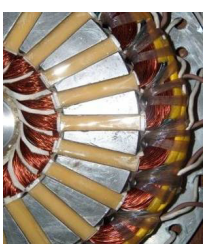

b)

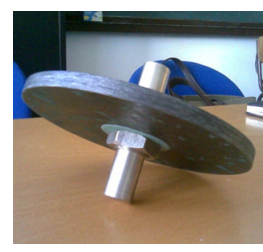

c)

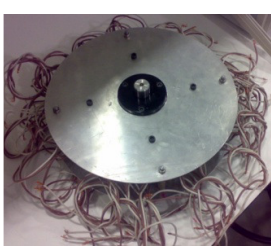

d)

Fig. 2. Built motor: a) steel semi-stator; $b$ ) double cooper layer slot stator winding, $c$ ) polycrystalline YBCO rotor and $d$ ) full motor with two semi-stators.

Spacing between the semi-stators and the rotor is regulated using adjustment nuts to ensure an airgap as small as possible. Dry bearings were used, after ultrasound treatment. The HTS material considered (YBCO) has a critical temperature of 90-92 $\mathrm{K}$. For that reason, liquid nitrogen was chosen to cool the system due to it boiling temperature of $77 \mathrm{~K}$.

\section{Supply System}

All the motor is submersed in liquid nitrogen during its operation. For that reason, the stator's cooper winding exhibit an electrical resistance significantly smaller when compared to room temperature, decreasing impedance. The input current was controlled by a $6 \mathrm{kVA}$ DC power supply (0-15 V/0-400 A). The stators were wound with copper conductors with a $0.8 \mathrm{~mm}^{2}$ cross section, allowing a maximum current of $8 \mathrm{~A}$ at room temperature. However, at liquid nitrogen temperature, this limit was considered superior.

As referred before, the rotor's magnetization was achieved using two semi-stators and a three-phase supply source, in bipolar and tetrapolar configurations, as showed in Fig. 3. In this figure a linear visualization of one semi-stator is illustrated.

Under normal operation the motor is supplied with a symmetric three-phase system as indicated in (2). In order to verify trapped flux capability of the rotor, only a static magnetization with three DC currents was applied. 


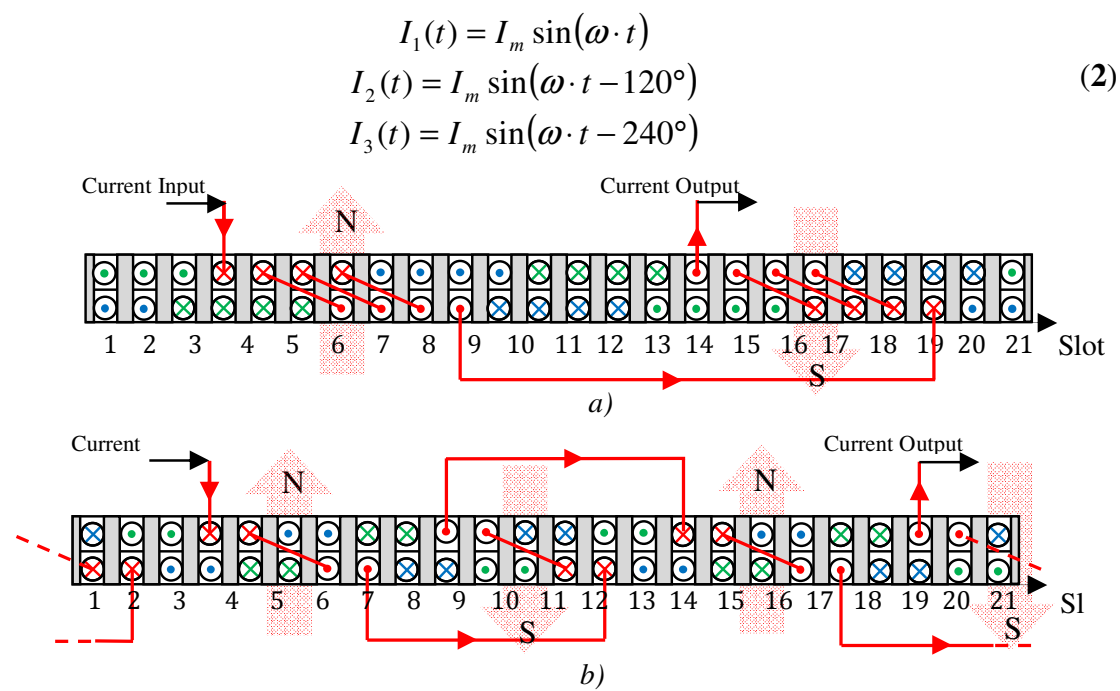

Fig. 3. Linear visualization of electrical connections, considering only phase 1 , for a) bipolar configuration and $b$ ) tetrapolar configuration.

Considering $t=0 \mathrm{~s}$, the DC current in phase 1 is zero, in phase 2 is $-I_{m} \cdot(\sqrt{3} / 2)$ and in phase 3 is $I_{m} \cdot \sqrt{(3 / 2)}$, where $I_{m}$ is the magnitude of the current.

\section{Data Acquisition System}

The necessity of operation in cryogenic environment implies a specific support system made of bakelite to fix the Hall probe. Bakelite was chosen due to its low linear expansion coefficient. The probe supply was performed using a double layer cooper plate connected to an electronic module that allows probe calibration and data acquisition. The system is illustrated in Fig. 4.

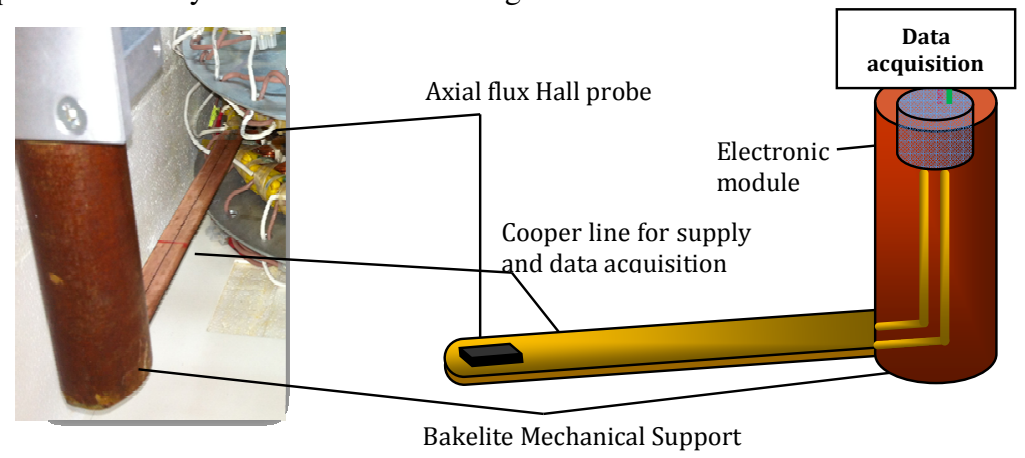

Fig. 4. Detail of the bakelite mechanical support for data acquisition. 
In order to obtain the matrix of magnetic field measurements, a three-dimensional computer-controlled positioner was used, allowing defining the xyz displacement and acquisition time. The data acquisition was performed as close as possible to the HTS disc, as detailed in Fig. 5. A data acquisition system was also used.

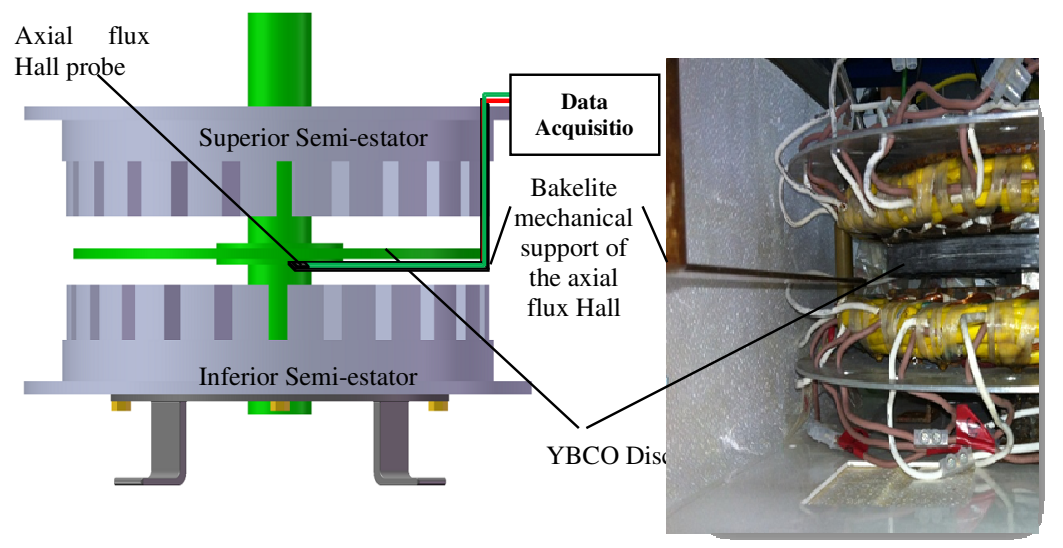

Fig. 5. Data acquisition system for recording data of the magnetic field mapping.

Due to symmetry, measurements were performed only in half disc. In order to ensure a constant and secure distance to the probe, the disc was shimmed between the semi-stators. All the system for data acquisition (Hall probe + calibration) was connected to a magnetometer that allowed determining deviations between the beginning and the end of the recording data. The xy displacement step was $1.5 \mathrm{~mm}$ with an acquisition time of 0.5 seconds, to ensure the field stabilization. Thus, each measurement run took approximately two hours, allowing obtaining about 4500 points of field.

\section{Obtained Magnetic Field Characteristic}

The goal of the measurements was determining flux density distribution due to semistators excitation, at room temperature, as well as in rotor (trapped flux), at cryogenic temperature.

\subsection{Magnetic Field Characteristic of Semi-Stators}

These measurements were perfomed with a tetrapolar configuration and a maximum current of 11.5 A. From (2), for $t=0 \mathrm{~s}$, the DC currents in phases 2 and 3 was $-10 \mathrm{~A}$ and $10 \mathrm{~A}$. These values were chosen in order to explore maximum current density of cooper windings, as the airgap was significantly increased to ensure scanning along 
the disc. Flux density measurements of semi-stators excitation at room temperature are showed in Fig. 6 a) for the entire disc, where it is possible to observe that it exhibits a maximum of $0.04 \mathrm{~T}$. Two poles pairs configuration are observed, as expected.

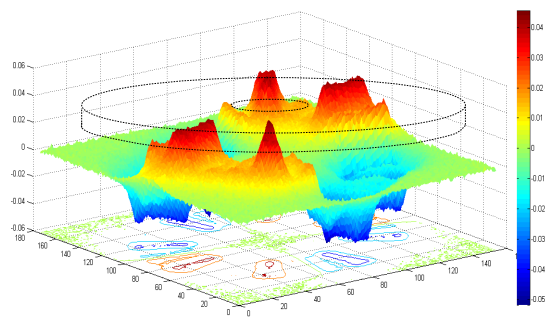

a)

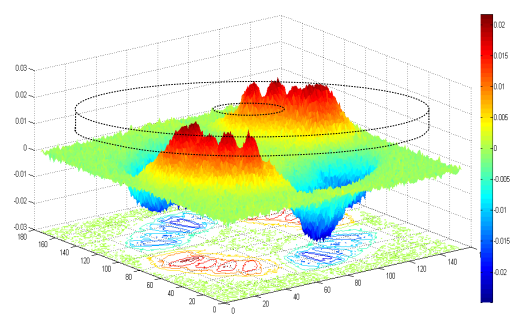

b)

Fig. 6. Magnetic induction distribution, for tetrapolar configuration, a) due semi-stators supply, at room temperature and $b$ ) trapped in the rotor, after magnetization, at cryogenic temperature.

\subsection{Magnetic Field Characteristic of Rotor}

As in previous measurements, this was performed using the tetrapolar configuration but at cryogenic temperature. Since the motor is submerged in liquid nitrogen, the stator's windings allow higher currents. The maximum current considered in this test was 34.6 A, leading to DC currents in phases 2 and 3 of $-30 \mathrm{~A}$ and $30 \mathrm{~A}$. The axial flux hall probe was calibrated for liquid nitrogen temperature.

After the magnetization, the supply system was turned off. Trapped flux mapping is showed in Fig. $(b$ ). As it is possible to observe, profile is similar to Fig. $6 a$ ), however, with different magnitudes, due to pinning characteristics of the material and since different currents were used in both measurements. From the comparison of Fig. $6 a$ ) and Fig. $6 b$ ) it is clear that the entire rotor is magnetized. 


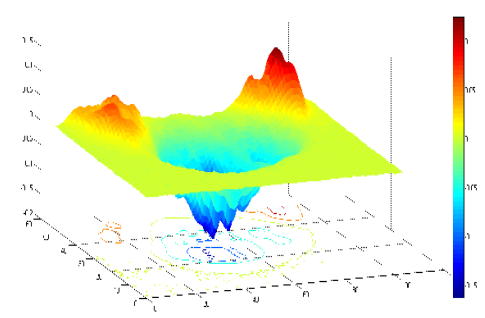

a)

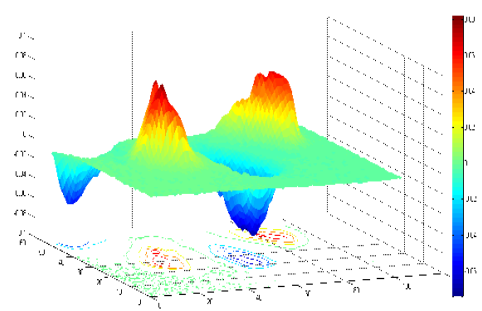

b)

Fig. 7. Magnetic induction in half disc for $a$ ) tetrapolar e $b$ ) octopolar configurations, at liquid nitrogen temperature for $I_{m}=127 \mathrm{~A}$.

As described in (1), the developed torque is proportional to the rotor's trapped flux. Thereby, higher values of current in the stators imply higher trapped flux, up to a certain limit. Magnetic induction is showed in Fig. 7 a) (trapped flux) in the rotor, in half the disc, for tetrpolar configuration and $I_{m}=127 \mathrm{~A}$. As is possible to observe, for a current 3.7 times higher, the trapped flux is, approximately, ten times higher. Measurements for the same current amplitude, but in octopolar configuration are showed in Fig. 7 b). It is possible to observe, in half disc, four poles, which means than in full disc eight poles are present, as expected. Nevertheless, for these values of current amplitude, magnetic saturation is present in the ferromagnetic circuit, which must be taken into account in a detailed analysis.

\section{Conclusions}

In this paper a preliminary study is presented, describing experimental mapping of the magnetic induction characteristics of axial flux disc motor with the rotor composed by polycrystalline high temperature superconductor. As torque is proportional to the number of pole pairs, these were changed by means of electrical connections in the armatures. Field profiles from rotor and stator were obtained at room and liquid nitrogen temperatures.

Flux profiles allow verifying number of poles. Moreover, it is possible to conclude that entire disc rotor is magnetized. Thus, it is expected that, when the motor operate in asynchronous regime, a maximum "theoretical" torque may be achieved, since this is proportional to the losses in the superconducting material.

Acknowledgments. The authors thank to CTS - UNINOVA and FCT (CTS multiannual funding - PIDDAC Program funds) for the financial support for the work.

\section{References}

1. Salama, K., Selvamanickan, V.: Joining of high current bulk YbaCuO superconductors, Appl. Phys. Lett., vol. 60, pp. 898--900 (1992) 
2. Lo, W., Cardwell, D.A., Bradley, A.D., Doyle, R.A., Shi, Y. H., Lloyd, S.: Development of nonweak link bulk YBCO grain boundaries for high magnetic field engineering applications, IEEE Trans. Appl. Supercond., vol. 9, pp. 2042--2045 (1999.)

3. Puig, F T., et al.: Self-seeded YBCO welding induced by Ag additives, Physica C, vol. 363, pp. 75-79 (2001)

4. Chen, C.L., Claus, H., Paulikas, A.P., Zheng, H., Veal, B.W.: Joining of melt-textured YBCO: A direct contact method, Supercond. Sci. Technol., vol. 15, pp. 1--3 (2002)

5. Inacio, D., Pina, J.M., Luis, G., Martins, J.F., Ventim-Neves, M., Alvarez, A.: Experimental Characterization of a Conventional (Aluminum) and of a Superconducting (YBCO) Axial Flux Disc Motor, Applied Superconductivity, IEEE Transactions on , vol.21, no.3, pp.1146$-1150(2011)$ 